\title{
Analysis of Turbofan Design Options for an Advanced Single-Aisle Transport Aircraft
}

\author{
Mark D. Guynn" \\ NASA Langley Research Center, Hampton, VA, 23681 \\ Jeffrey J. Berton, ${ }^{\dagger}$ Kenneth L. Fisher, ${ }^{\ddagger}$ William J. Haller, ${ }^{\S}$ and Michael T. Tong ${ }^{* *}$ \\ NASA Glenn Research Center, Cleveland, Ohio, 44135 \\ and \\ Douglas R. Thurman ${ }^{\dagger \dagger}$ \\ Army Research Lab, Cleveland, Ohio, 44135
}

\begin{abstract}
The desire for higher engine efficiency has resulted in the evolution of aircraft gas turbine engines from turbojets, to low bypass ratio, first generation turbofans, to today's high bypass ratio turbofans. It is possible that future designs will continue this trend, leading to very-high or ultra-high bypass ratio (UHB) engines. Although increased bypass ratio has clear benefits in terms of propulsion system metrics such as specific fuel consumption, these benefits may not translate into aircraft system level benefits due to integration penalties. In this study, the design trade space for advanced turbofan engines applied to a single-aisle transport (737/A320 class aircraft) is explored. The benefits of increased bypass ratio and associated enabling technologies such as geared fan drive are found to depend on the primary metrics of interest. For example, bypass ratios at which fuel consumption is minimized may not require geared fan technology. However, geared fan drive does enable higher bypass ratio designs which result in lower noise. Regardless of the engine architecture chosen, the results of this study indicate the potential for the advanced aircraft to realize substantial improvements in fuel efficiency, emissions, and noise compared to the current vehicles in this size class.
\end{abstract}

\section{Nomenclature}

$\begin{array}{ll}\text { ADP } & =\text { Aerodynamic Design Point } \\ \text { ANOPP } & =\text { Aircraft Noise Prediction Program } \\ \text { ASAT } & =\text { Advanced Single-Aisle Transport } \\ \text { BPR } & =\text { Bypass Ratio } \\ \text { EIS } & =\text { Entry-Into-Service } \\ \text { EPNL } & =\text { Effective Perceived Noise Level } \\ \text { FAR } & =\text { Federal Aviation Regulations } \\ \text { FLOPS } & =\text { Flight Optimization System } \\ \text { FPR } & =\text { Fan Pressure Ratio } \\ \text { HPC } & =\text { High Pressure Compressor } \\ \text { HPT } & =\text { High Pressure Turbine } \\ \text { LPC } & =\text { Low Pressure Compressor }\end{array}$

\footnotetext{
* Aerospace Engineer, Aeronautics Systems Analysis Branch, MS 442, Senior Member AIAA.

${ }^{\dagger}$ Aerospace Engineer, Multidisciplinary Design \& Optimization Branch, MS 5-11.

$\ddagger$ Aerospace Engineer, Multidisciplinary Design \& Optimization Branch, MS 5-11, Member AIAA.

$\S$ Aerospace Engineer, Multidisciplinary Design \& Optimization Branch, MS 5-11, Member AIAA.

** Aerospace Engineer, Multidisciplinary Design \& Optimization Branch, MS 5-11, Member AIAA.

${ }^{\dagger \dagger}$ Aerospace Engineer, Multidisciplinary Design \& Optimization Branch, MS 5-11.
} 


$\begin{array}{ll}\text { LPT } & =\text { Low Pressure Turbine } \\ \text { LTO } & =\text { Landing-Takeoff Cycle } \\ \text { NPSS } & =\text { Numerical Propulsion System Simulation } \\ \text { OEW } & =\text { Operating Empty Weight } \\ \text { OPR } & =\text { Overall Pressure Ratio } \\ \text { PDCYL } & =\text { Point Design of Cylindrical-bodied aircraft } \\ \text { TOC } & =\text { Top-Of-Climb } \\ \text { TSFC } & =\text { Thrust Specific Fuel Consumption } \\ \text { UHB } & =\text { Ultra-High Bypass ratio } \\ \text { WATE } & =\text { Weight Analysis of Turbine Engines }\end{array}$

\section{Introduction}

A S aircraft manufacturers Boeing and Airbus continue to develop and mature new twin-aisle, wide body aircraft designs in the 210-350 seat class, for scheduled first deliveries in 2010 and 2013 respectively, it is anticipated that the next major development undertaking for both companies will be a new narrow body aircraft in the Boeing 737/Airbus A320 class. Boeing and Airbus have been engaged in studies to investigate replacement designs for the 737 and A320, and published reports indicate that both manufacturers are depending on a next generation engine to power these new designs. ${ }^{1}$ What has yet to be decided is the most attractive advanced engine design for this class of aircraft in light of the current metrics of interest in the aviation industry.

The large fuel consumption and operating cost reductions necessary to make a new single-aisle transport design economically viable will require substantial improvements in propulsion system efficiency. In the past, the desire for higher engine efficiency has resulted in the evolution of aircraft gas turbine engines from turbojets (bypass ratio (BPR) of 0 ), to low bypass ratio, first generation turbofans (BPR=1-2), to today's high bypass ratio turbofans (BPR=5-10). It is possible that engines for the 737/A320 replacement will continue this trend, leading to very-high or ultra-high bypass ratio (UHB) engines. Because of the potential for improved propulsive efficiency, and the complementary benefit of lower engine noise, the use of UHB engines has been studied many times over the past several decades and there are numerous publications addressing the topic. References 2 through 4 provide a few examples. Results published over the years include both positive and negative assessments of UHB engines, depending on the assumptions made and the metrics of interest.

Over time the baseline technologies, market environment (e.g., fuel cost), metrics of interest, and target applications change, dictating that concepts such as the UHB engine be periodically revisited. In recent years, fuel efficiency, emissions, and noise have become key metrics for aircraft/engine performance. Rising fuel costs have greatly elevated the importance of fuel efficiency to the overall profitability of airlines and the success of an aircraft design. Noise and emissions are also projected to be of increasing importance in aircraft design as the demand for air travel grows. Substantial reductions in aircraft noise and emissions are required to enable unconstrained aviation growth without a sharply increasing negative impact on the environment. The 737/A320 class aircraft considered in this study represent a significant portion of the global airline fleet. Sixty-five percent of the new aircraft produced over the next 20 years are projected to be in this class. ${ }^{5}$ Advances made to reduce the noise and emissions of these aircraft could provide a considerable positive contribution to the goal of minimizing the future environmental impact of aviation.

\section{Study Objectives and Approach}

The primary objective of this advanced single-aisle transport (ASAT) engine concept study was to determine if the thrust specific fuel consumption (TSFC) and noise benefits of higher bypass ratio engines translate into overall aircraft system level benefits for a 737 class vehicle entering service in the 2015-2020 time frame. (The scope of this study was limited to ducted turbofan engines, open rotor designs may also be viable candidates for a future ASAT aircraft and are the focus of a separate study.) The approach taken was to develop a series of analytical engine models, apply them to a common airframe model, and assess the overall performance and noise characteristics. The main parameter of interest for the study was design fan pressure ratio (FPR). Bypass ratio is inversely proportional to fan pressure ratio. As fan pressure ratio is reduced, to maintain thrust fan mass flow must increase, which results in higher bypass ratio. It was quickly determined during the initial stages of the study that other key engine design choices have a significant impact on the effects of fan pressure ratio and the number of trade parameters was expanded. The study was conducted in three analysis "spirals" having different design ground rules and assumptions. Each spiral resulted in 16 different configurations for a total of 48 engine/airframe combinations which 
were analyzed for performance and noise characteristics. This paper presents a brief overview of the study and a summary of the results, additional details are provided in reference 6 .

\section{Modeling and Analysis Methodology}

\section{A. Propulsion System Modeling}

Since the propulsion system was the primary area of focus for this study, a substantial amount of effort was applied to building analytical models of the study engines. Developing models which were adequately representative of engines that could be available for a 737/A320 replacement aircraft was an important objective. However, just as important was the requirement of consistency among the engine models. After reviewing available material on projected advanced propulsion technologies for the 2015 timeframe, the propulsion systems analysis team developed a common design approach and set of technology assumptions which were utilized throughout to enable this consistency. The unique characteristics of individual engine architectures may make some assumptions less appropriate for certain engines types. This makes applying consistent ground rules and technology assumptions across such a wide range of engine designs problematic. The degree to which the resulting study engines are truly equivalent in technology and design optimality is uncertain.

The basic engine architecture for all the engines in this study was a two spool, separate flow turbofan. The variations evaluated included the fan drive approach (geared vs. direct drive), the fan pressure ratio, the low spoolhigh spool compression work split, the type of fan nozzle (fixed or variable geometry), the overall pressure ratio, and the design Mach number. For a given analysis spiral, all engines were developed with the same Aerodynamic Design Point (ADP) (Mach number, altitude, and thrust) and same overall pressure ratio at that point. The ADP was selected to represent a nominal top-of-climb (TOC) condition for the advanced airframe. Although for a given spiral the overall pressure ratio is the same for all the engines, two different compressor work splits were considered. For a given fan pressure ratio and overall pressure ratio, the "low work" engines have a lower pressure rise across the low pressure compressor (and a higher pressure rise across the high pressure compressor) compared to the "high work" engines. Inlet mass flow for each engine was selected to achieve the net thrust requirement at ADP. In addition to meeting a thrust target at TOC conditions, a SLS thrust target of $23,000 \mathrm{lb}$ (hot day, ISA $+27^{\circ} \mathrm{F}$ ) was also met by adjusting design point burner fuel-to-air ratio. Low fan pressure ratio engines inherently have a greater loss of thrust with airspeed (thrust lapse) than high fan pressure ratio engines. To achieve equal ADP thrust capability, the low fan pressure ratio engines are operated at higher temperatures. The ADP operating temperatures for the low fan pressure ratio engines were below the maximums allowed for the materials assumed, but the higher temperatures could still lead to shorter engine hot section life and greater maintenance requirements than the high fan pressure ratio engines. Engine life and maintenance issues were not assessed as part of this study. For low fan pressure ratio engines, a variable area fan exhaust nozzle was needed to maintain adequate fan surge margin. Throat area of the variable area nozzle was varied at off-design to maintain the fan operating conditions equal to, or very close to, the fan peak efficiency operating line. Cycle analysis for the engines was performed with the NPSS (Numerical Propulsion System Simulation) code. ${ }^{7-9}$ Analysis of the aeromechanical characteristics and estimates of the engine weight (including fan gearbox if applicable) were performed with the WATE (Weight Analysis of Turbine Engines) code. ${ }^{10-}$

${ }_{12}$ Estimates for engine $\mathrm{NO}_{\mathrm{X}}$ emission indices (grams of $\mathrm{NO}_{\mathrm{X}}$ emitted from the engine per kilogram of fuel consumed by the engine) were obtained from a correlation developed by NASA combustor technologists during the latter stages of NASA's Ultra-Efficient Engine Technology program.

\section{B. Aircraft Sizing Analysis}

To evaluate and compare aircraft system level performance, the study engines were combined with an advanced technology, single-aisle commercial transport airframe model. The aircraft sizing and synthesis computer code FLOPS (Flight Optimization System) ${ }^{13}$ was used as the primary aircraft level sizing and analysis tool. Since the objective of the study was a comparison of engine concepts, the primary modeling focus was the propulsion system. However, inaccuracies in the airframe model can skew the system level impacts of the engine designs and influence the overall conclusions. Special sizing considerations introduced by large diameter, UHB engines were addressed through simplifying assumptions and enhancements to the FLOPS analysis. Spreadsheet analyses were used to determine landing gear length, engine-out drag, and required vertical tail size so that impacts of large diameter engines could be properly captured. Enhancements to basic FLOPS capabilities were also made in the structural weight and aerodynamics areas. The wing and fuselage structural weight estimates of FLOPS were replaced with estimates from PDCYL. PDCYL offers a less empirical, more analytical weight estimation methodology that is more sensitive to parameters such as engine weight and location. ${ }^{14}$ FLOPS aerodynamic predictions were enhanced 
through a model calibration process incorporating details of the 737-800 high speed and low speed aerodynamic performance.

\section{Baseline Airframe Model}

The Boeing 737-800 (with winglets) was used as a starting point for development of the ASAT airframe model. A baseline FLOPS model of a 737-800 like aircraft (162 passenger, mixed-class configuration) was developed using a combination of publicly available data on the 737-800 geometry, weight, and performance characteristics; ${ }^{15}$ a CFM56-7B based engine model developed at NASA Glenn; and proprietary aerodynamic data. Model weight predictions were calibrated by setting maximum ramp weight and landing weight to the Boeing reported values $(174,700 \mathrm{lb}$ and $146,300 \mathrm{lb}$ respectively) and comparing the predicted operating empty weight (OEW) to the Boeing data. Although the model OEW matched the Boeing data to within $0.5 \%$, calibration adjustments were made to the model to match OEW exactly. FLOPS aerodynamic predictions were calibrated to 737-800 high speed aerodynamic data. It was not possible to exactly match the 737-800 data at all conditions; however, it was possible to obtain an excellent match around the cruise flight conditions. FLOPS predicted mission performance was calibrated to a specific point on the 737-800 payload-range diagram provided in reference 15. Prior to adjustments, the FLOPS predicted range for the calibration point was $\sim 4 \%$ high. Assuming that the mission profile is adequately modeled and the aerodynamic model is accurate, the higher FLOPS range is indicative of an under prediction of engine TSFC. The NASA-developed engine deck was therefore adjusted so that the FLOPS results matched published range capability. Note that it is not possible to separate the impacts of inaccuracies in mission profile, engine TSFC, and aircraft L/D when matching range performance. Even though adjustment was only made to the engine model, the discrepancy is most likely due to a combination of differences in engine characteristics, aerodynamic characteristics, and mission definition. Evaluation and calibration of the FLOPS model was also performed for takeoff and landing performance. After some adjustment to the inputs based on 737-800 aerodynamic data, takeoff and landing distances for nominal conditions were matched to within $\sim 1.0 \%$ of the reported values.

\section{ASAT Airframe Model}

The ASAT airframe model is a derivative of the 737-800 like baseline discussed above, intended to be representative of a potential advanced technology replacement aircraft. A conventional airframe-engine layout like the 737-800 was assumed based on the hypothesis that unconventional approaches are not sufficiently mature to support the expected entry-into-service (EIS) date for this vehicle. The primary airframe technology advancement assumed was extensive use of composite materials for the airframe structure. For the Boeing 787 currently in development, as much as 50 percent of the primary structure is made of composite materials. ${ }^{\ddagger \neq}$ Other minor technology improvements based on the 787 design included an increase in hydraulic pressure and a slight drag reduction. Changes were also made to the design mission to reflect performance enhancements projected for an advanced aircraft in this vehicle class. Design range (with 32,400 lb payload) was increased from $3060 \mathrm{~nm}$ to 3250 $\mathrm{nm}$. Two cruise Mach numbers were analyzed, 0.72 and 0.80 (typical cruise Mach for the 737-800 is $0.785^{15}$ ). The basic 737-800 geometry was not changed for the ASAT model, except for changes in wing sweep corresponding to the changes in cruise Mach number.

\section{Propulsion-Airframe Integration}

Propulsion-airframe integration is one of the key considerations for large diameter, UHB engines. Reference 4 provides an excellent summary of the integration issues associated with large diameter engines and was used as a basis for the current study. Concerns highlighted in reference 4 include nacelle drag, ground clearance, windmilling drag, thrust reverser operation, and engine placement. These concerns were addressed to varying degrees in the study. A simple geometric method was developed to estimate the required landing gear length. Windmilling and engine-out drag estimates were made using handbook methods ${ }^{16}$ and the vertical tail was sized based on consideration of both tail volume coefficient and one-engine-out control. Some propulsion-airframe integration issues were outside the scope of this study. Examples of issues outside the scope of this study include impacts of nacelle diameter on pylon and flap design and potential changes in thrust reverser operation associated with large diameter engines. (An estimate of thrust reverser weight was included for all engines, however.)

\section{Noise Analysis}

The primary tools used for the noise analysis included: NPSS for the engine cycle analysis; WATE for the engine aeromechanical and flowpath analysis; FLOPS for the aircraft trajectory simulation; and ANOPP (Aircraft Noise Prediction Program) Level $26^{17,18}$ for the source noise prediction and propagation. The NPSS and WATE codes were used to generate input data necessary for the ANOPP source noise modeling. Adjustments representing noise reduction technologies were made to the source noise spectra prior to propagation. ANOPP noise propagation

$\$ 787$ Dreamliner Program Fact Sheet. http://ww.boeing.com/commercial/787family/programfacts.html. Accessed 4/9/2007. 
modeling included spherical spreading, atmospheric attenuation, ground effects, reflections, and lateral attenuation. The Effective Perceived Noise Level (EPNL) was calculated at the noise certification points defined in FAR Part $36 .^{19}$ EPNL is an integration of the ground observer perceived noise time history which depends on aircraft trajectory, noise spectra propagation, frequency integration, and tonal content and amplitude penalties.

The noise analysis tools were first used to model a 737-800/CFM56-7B and the analytical results were compared to noise certification data for that airplane. ${ }^{20}$ The CFM56-7B was analytically modeled in NPSS using data available from several public-domain sources, no proprietary data were used. The thermodynamic, aeromechanical, and geometric predictions for the CFM56-7B were used as inputs to ANOPP's current propulsion source noise prediction methods. Good agreement between the certification data and analytical prediction was obtained for the lateral (sideline) and approach conditions. Noise at the flyover condition was over predicted by approximately 4 EPNdB. Through more detailed analysis and comparison of predicted source noise levels to proprietary data it was determined that the fan noise predictions might be about $5 \mathrm{~dB}$ too high at the flyover, cutback power setting. There are many sources of uncertainty in the noise analysis process, however, including the engine cycle and aeromechanical modeling (NPSS and WATE), the trajectory and throttle setting assumptions, and numerous other potential discrepancies. Because the exact cause of the error cannot be readily determined and the level of error in the results was deemed acceptable for this comparative study, no attempt was made to calibrate the noise analysis tools and eliminate the discrepancy between predicted and actual 737-800 noise levels.

A series of advanced noise reduction technologies were applied to the study configurations consistent with the 2015-2020 EIS target for the vehicle. Chevrons were applied to all core nozzles and to all fixed-area bypass nozzles. Chevrons were not applied to bypass nozzles of the low fan pressure ratio engines with variable area nozzles due to potential conflict with the variable area nozzle design. Jet noise benefits of the nozzle chevrons were determined analytically using the 2004 Stone jet noise prediction method in ANOPP. ${ }^{21}$ This method is based on 1997 acoustic measurements of chevron-equipped nozzles from NASA Glenn's Aeroacoustic Propulsion Laboratory's Nozzle Acoustic Test Rig freejet facility. ${ }^{22}$ Conventional inlet, interstage, and aft fan duct liners were applied to reduce fan inlet and discharge noise. The benefits of these liners were modeled by applying an acoustic suppression "map" of $1 / 3$ rd octave band sound pressure level decrements to the hardwall fan source spectra predicted by ANOPP. This approach differs from the 737-800/CFM56-7B validation study described above, where ANOPP's built-in treatment suppression prediction modul ${ }^{23}$ was used, since a more aggressive treatment configuration would likely be used in an advanced engine. The liner suppression map was based on measured acoustic data of 22-inch diameter fan test articles in NASA Glenn's $9 \times 15$ Low Speed Wind Tunnel. ${ }^{24}$ In addition to conventional liners, two advanced technologies were applied for fan noise reduction; soft vane stators and over-the-rotor foam metal treatment. ${ }^{25}$ Both of these technologies are applications of acoustic treatment in areas of the engine which currently do not have treatment: the fan vanes and above the fan rotor tips. Acoustic tests of both of these technologies were conducted at NASA Glenn in 2008. Airframe noise reduction technologies included innovative slat cove designs, flap porous tips, and landing gear fairings. These technologies are considered mature enough to be commensurate with the assumed EIS timeframe.

Higher bypass ratio, lower fan pressure ratio engines have inherently higher thrust lapse (i.e., available thrust decreases more rapidly with increase in aircraft speed). The impact of higher thrust lapse is manifested in changes in climb rates, airspeeds, and throttle settings for takeoff and landing trajectories. Certification noise is impacted by these trajectory changes since propulsion noise is a strong function of throttle setting, airframe noise is a strong function of airspeed, and altitude and distance from the observer strongly affect noise from all sources. Detailed departure and approach trajectories were modeled in FLOPS to enable these engine dependent characteristics to be captured in the analysis, which in turn enabled the influence of trajectory on the noise results to be properly captured.

\section{Study Trade Space}

As mentioned previously, the study was conducted in three separate analysis spirals. The primary differences between the three spirals were engine overall pressure ratio at ADP and ADP/cruise Mach number. All of the engines in Spiral 1 were designed with an overall pressure ratio (at the top-of-climb ADP) of 32. This overall pressure ratio is similar to that of the CFM56 engines that are used on the current Boeing 737 and Airbus A320. Current technology large engines can have overall pressure ratios above 40. Although technology advances can lead to higher overall pressure ratios, higher pressure ratios lead to smaller compressor blades. There are limits to how small a compressor blade can be manufactured and the smaller the blade becomes the less efficient it is due to exaggerated blade tip clearance losses and Reynolds number effects. For these reasons it is not possible to simply scale down a high overall pressure ratio $80,000 \mathrm{lb}$ thrust engine to a $25,000 \mathrm{lb}$ thrust engine. In Spiral 1 , a 
conventional, fairly conservative design approach was taken which enabled a design overall pressure ratio of 32 while maintaining blade heights greater than 0.5 inches. Design parameters for the Spiral 1 engines are summarized in Table 1.

Table 1. Spiral 1 Engine Design Parameters

\begin{tabular}{|l|c|c|c|c|c|c|c|}
\hline Engine Designation & Fan Drive & Fan Nozzle & ADP & FPR & OPR & LPC PR & HPC PR \\
\hline S1_Lo_dd_fpr14_VAN & Direct & Variable & M0.80/35kft & 1.4 & 32 & 1.69 & 13.5 \\
\hline S1_Lo_dd_fpr15_fixed & Direct & Fixed & M0.80/35kft & 1.5 & 32 & 1.58 & 13.5 \\
\hline S1_Lo_dd_fpr16_fixed & Direct & Fixed & M0.80/35kft & 1.6 & 32 & 1.48 & 13.5 \\
\hline S1_Lo_dd_fpr17_fixed & Direct & Fixed & M0.80/35kft & 1.7 & 32 & 1.39 & 13.5 \\
\hline S1_Lo_g_fpr13_VAN & Geared & Variable & M0.80/35kft & 1.3 & 32 & 1.82 & 13.5 \\
\hline S1_Lo_g_fpr14_VAN & Geared & Variable & M0.80/35kft & 1.4 & 32 & 1.69 & 13.5 \\
\hline S1_Lo_g_fpr15_fixed & Geared & Fixed & M0.80/35kft & 1.5 & 32 & 1.58 & 13.5 \\
\hline S1_Lo_g_fr16_fixed & Geared & Fixed & M0.80/35kft & 1.6 & 32 & 1.48 & 13.5 \\
\hline S1_Hidddfpr14_VAN & Direct & Variable & M0.80/35kft & 1.4 & 32 & 2.29 & 10.0 \\
\hline S1_Hi_dd_fpr15_fixed & Direct & Fixed & M0.80/35kft & 1.5 & 32 & 2.13 & 10.0 \\
\hline S1_Hi_dd_fpr16_fixed & Direct & Fixed & M0.80/35kft & 1.6 & 32 & 2.00 & 10.0 \\
\hline S1_Hi_dd_fpr17_fixed & Direct & Fixed & M0.80/35kft & 1.7 & 32 & 1.88 & 10.0 \\
\hline S1_Higgfpr13_VAN & Geared & Variable & M0.80/35kft & 1.3 & 32 & 2.46 & 10.0 \\
\hline S1_Hi_g_fpr14_VAN & Geared & Variable & M0.80/35kft & 1.4 & 32 & 2.29 & 10.0 \\
\hline S1_Hi_g_fpr15_fixed & Geared & Fixed & M0.80/35kft & 1.5 & 32 & 2.13 & 10.0 \\
\hline S1_Hig_fpr16_fixed & Geared & Fixed & M0.80/35kft & 1.6 & 32 & 2.00 & 10.0 \\
\hline
\end{tabular}

Based on projections of a higher overall pressure ratio for an advanced engine of this class, a second set of analyses, Spiral 2, was conducted with a more aggressive design approach to enable an increase in overall pressure ratio to 42 . In particular, the minimum blade height constraint was relaxed. The engine design parameters for Spiral 2 are shown in Table 2. Changes in the low pressure compressor (LPC) and high pressure compressor (HPC) pressure ratios associated with the higher overall pressure ratio can be seen by comparison to Table 1 .

Table 2. Spiral 2 Engine Design Parameters

\begin{tabular}{|l|c|c|c|c|c|c|c|}
\hline Engine Designation & Fan Drive & Fan Nozzle & ADP & FPR & OPR & LPC PR & HPC PR \\
\hline S2_Lo_dd fpr14_VAN & Direct & Variable & M0.80/35kft & 1.4 & 42 & 1.69 & 17.7 \\
\hline S2_Lo_dd_fpr15_fixed & Direct & Fixed & M0.80/35kft & 1.5 & 42 & 1.58 & 17.7 \\
\hline S2_Lo_dd_fpr16_fixed & Direct & Fixed & M0.80/35kft & 1.6 & 42 & 1.48 & 17.7 \\
\hline S2_Lo_dd fpr17_fixed & Direct & Fixed & M0.80/35kft & 1.7 & 42 & 1.39 & 17.7 \\
\hline S2_Lo_g_fpr13_VAN & Geared & Variable & M0.80/35kft & 1.3 & 42 & 1.82 & 17.7 \\
\hline S2_Lo_g_fpr14_VAN & Geared & Variable & M0.80/35kft & 1.4 & 42 & 1.69 & 17.7 \\
\hline S2_Lo_g fpr15_fixed & Geared & Fixed & M0.80/35kft & 1.5 & 42 & 1.58 & 17.7 \\
\hline S2_Lo_g_fpr16_fixed & Geared & Fixed & M0.80/35kft & 1.6 & 42 & 1.48 & 17.7 \\
\hline S2_Hi_dd_fpr14_VAN & Direct & Variable & M0.80/35kft & 1.4 & 42 & 2.50 & 12.0 \\
\hline S2_Hi_dd fpr15_fixed & Direct & Fixed & M0.80/35kft & 1.5 & 42 & 2.33 & 12.0 \\
\hline S2_Hi_dd_fpr16_fixed & Direct & Fixed & M0.80/35kft & 1.6 & 42 & 2.19 & 12.0 \\
\hline S2_Hi_dd_fpr17_fixed & Direct & Fixed & M0.80/35kft & 1.7 & 42 & 2.06 & 12.0 \\
\hline S2_Higgfpr13_VAN & Geared & Variable & M0.80/35kft & 1.3 & 42 & 2.69 & 12.0 \\
\hline S2_Hi_g_fpr14_VAN & Geared & Variable & M0.80/35kft & 1.4 & 42 & 2.50 & 12.0 \\
\hline S2_Hi_g_fpr15_fixed & Geared & Fixed & M0.80/35kft & 1.5 & 42 & 2.33 & 12.0 \\
\hline S2_Hig_fpr16_fixed & Geared & Fixed & M0.80/35kft & 1.6 & 42 & 2.19 & 12.0 \\
\hline
\end{tabular}

The design cruise Mach number selected for the Spiral 1 and Spiral 2 advanced vehicle designs was 0.80, compared to a long range cruise Mach number of 0.785 for the $737-800$. Some have suggested that to increase fuel efficiency 
the replacement aircraft for the Boeing 737 and Airbus A320 families will actually be designed to fly significantly slower. Because of environmental and economic pressures, airlines may be willing to give up something in productivity (speed) for reduced fuel consumption. For Spiral 3, the cruise Mach number was reduced to 0.72 to assess the impact of cruise Mach number on the relative system level performance for the different engine types. (A table of the Spiral 3 engine design parameters is not shown since the only difference compared to Table 2 is an ADP Mach number of 0.72 instead of 0.80 .)

\section{Summary of Results}

Figures 1 through 5 attempt to consolidate and summarize the large amount of data generated during this study. In these figures, the four different basic engine architectures (low work-geared, low work-direct drive, high workgeared, and high work-direct drive) have been collapsed into a single curve by plotting the minimum value among the four for a given fan pressure ratio and Spiral. The engine configuration to which this value corresponds is also indicated. (Note that in some cases the minimum value is not significantly less than that obtained from the other engine architectures.) Figure 1, ramp weight, illustrates the weight penalty associated with low fan pressure ratio, which was found consistently across the analysis Spirals. Also, there is a clear preference for high work, geared designs at fan pressure ratios up to 1.5 and low work, direct drive engines at higher fan pressure ratios. Higher overall pressure ratio (Spirals $2 \& 3$ ) and lower Mach (Spiral 3) both reduce ramp weight. For block fuel, shown in Fig. 2, there is again consistently a penalty for very low fan pressure ratio engines. The reduction in takeoff performance for these engines (due to thrust lapse) coupled with higher aircraft weight leads to higher required thrust than the nominal 23,000 lb SLS design value. Although engine scaling laws were used to provide approximate characteristics for the higher thrust engines required, the low fan pressure ratio cases could potentially benefit from redesigned engines that meet takeoff thrust requirements without scaling. The minimum block fuel consumption consistently occurs in the 1.55 to 1.6 fan pressure ratio range (analysis was only conducted at 1.5 and 1.6; the minimum shown between those two points is the result of curve fitting the data and may not be the exact minimum). As with ramp weight, geared engines are preferred below a fan pressure ratio of 1.5 and direct drive engines above. Comparing the Spirals it is evident that both higher overall pressure ratio and lower cruise Mach reduce fuel consumption. In the block $\mathrm{NO}_{\mathrm{x}}$ chart, Fig. 3 , all the minimum points are high work engines since the low work engines have slightly higher $\mathrm{NO}_{\mathrm{x}}$ emissions. Similar to ramp weight, the trend is for block $\mathrm{NO}_{\mathrm{x}}$ to decrease with increasing fan pressure ratio, at least up to the highest fan pressure ratio analyzed. In the case of block $\mathrm{NO}_{\mathrm{x}}$, gearing is beneficial up to fan pressure ratio of 1.6. The increase in overall pressure ratio for Spiral 2 significantly increases the block $\mathrm{NO}_{\mathrm{x}}$, while the lower cruise Mach in Spiral 3 results in a reduction in block $\mathrm{NO}_{\mathrm{x}}$. The trends of landingtakeoff cycle (LTO) $\mathrm{NO}_{\mathrm{x}}$, shown in Fig. 4, are not as consistent as the other metrics. High fan pressure ratio certainly leads to higher LTO $\mathrm{NO}_{\mathrm{x}}$, but between $\mathrm{FPR}=1.3$ and 1.5 the variation with fan pressure ratio is not consistent. LTO $\mathrm{NO}_{\mathrm{X}}$ results depend on a combination of the engine characteristics and the aircraft sizing results (e.g., trade between engine thrust and wing area necessary to meet takeoff performance); therefore, they exhibit more variability. For certification noise the dominant factor is clearly fan pressure ratio as evident in Fig. 5. (Noise results are presented in terms of the sum of the noise levels at the three certification points, so-called "cumulative noise.") Although the minimum noise cases were mostly configurations with high work, geared engines, there was in fact little variability in noise results among the different engine architectures. Regardless of the type of engine, the overall pressure ratio, or the airplane/engine design Mach number, noise for a given fan pressure ratio was approximately the same. Furthermore, the variation of noise with fan pressure is greater than the variation in the weight, fuel consumption, or emissions. 


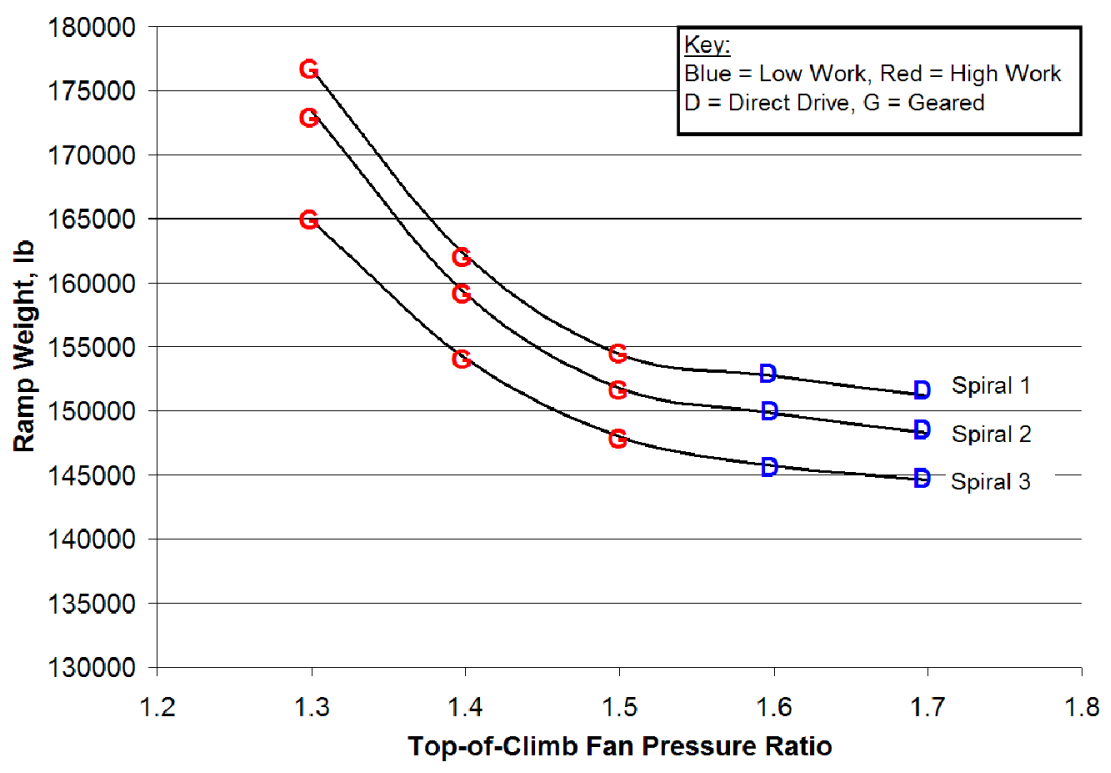

Figure 1. Variation of ramp weight with fan pressure ratio.

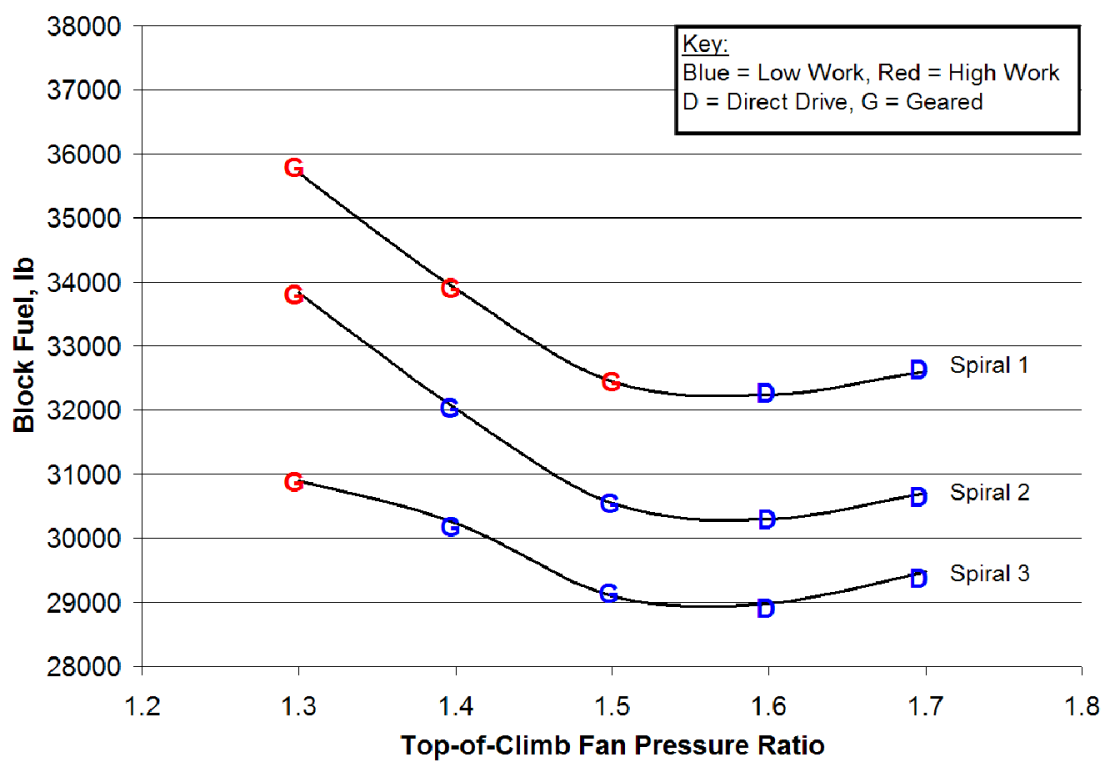

Figure 2. Variation of block fuel with fan pressure ratio. 


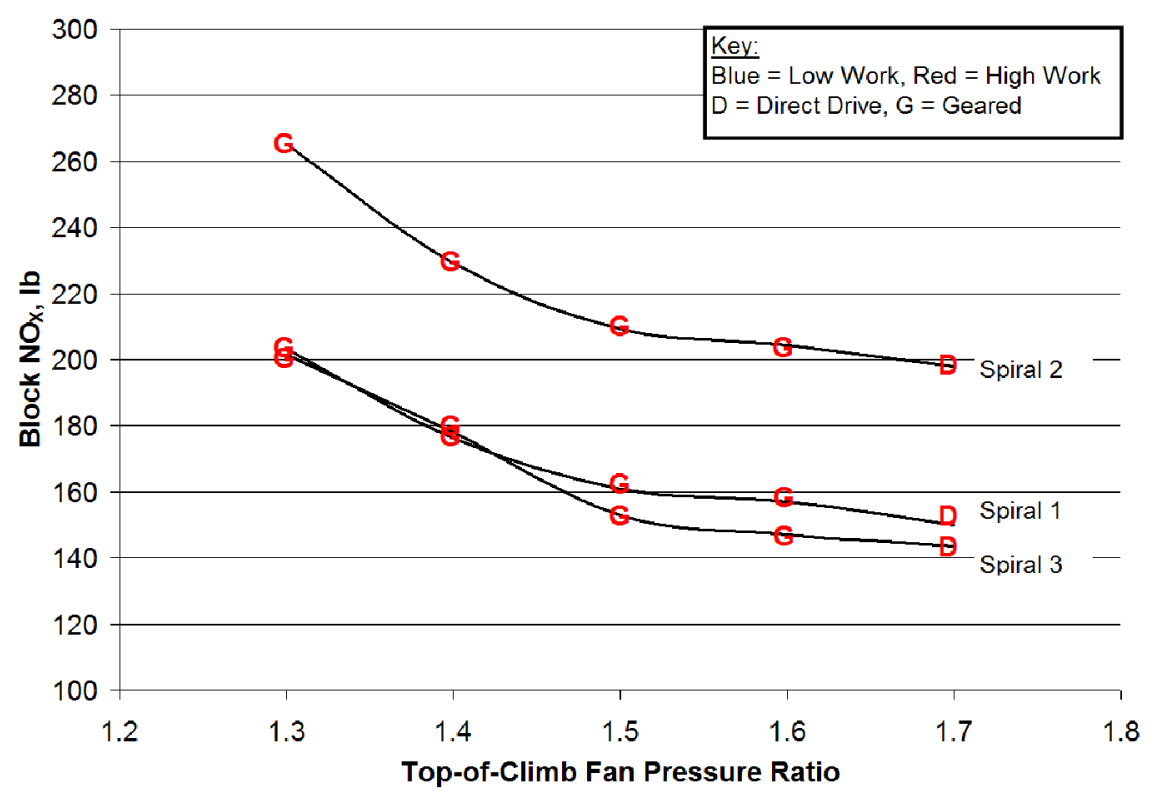

Figure 3. Variation of block $\mathrm{NO}_{\mathrm{x}}$ with fan pressure ratio.

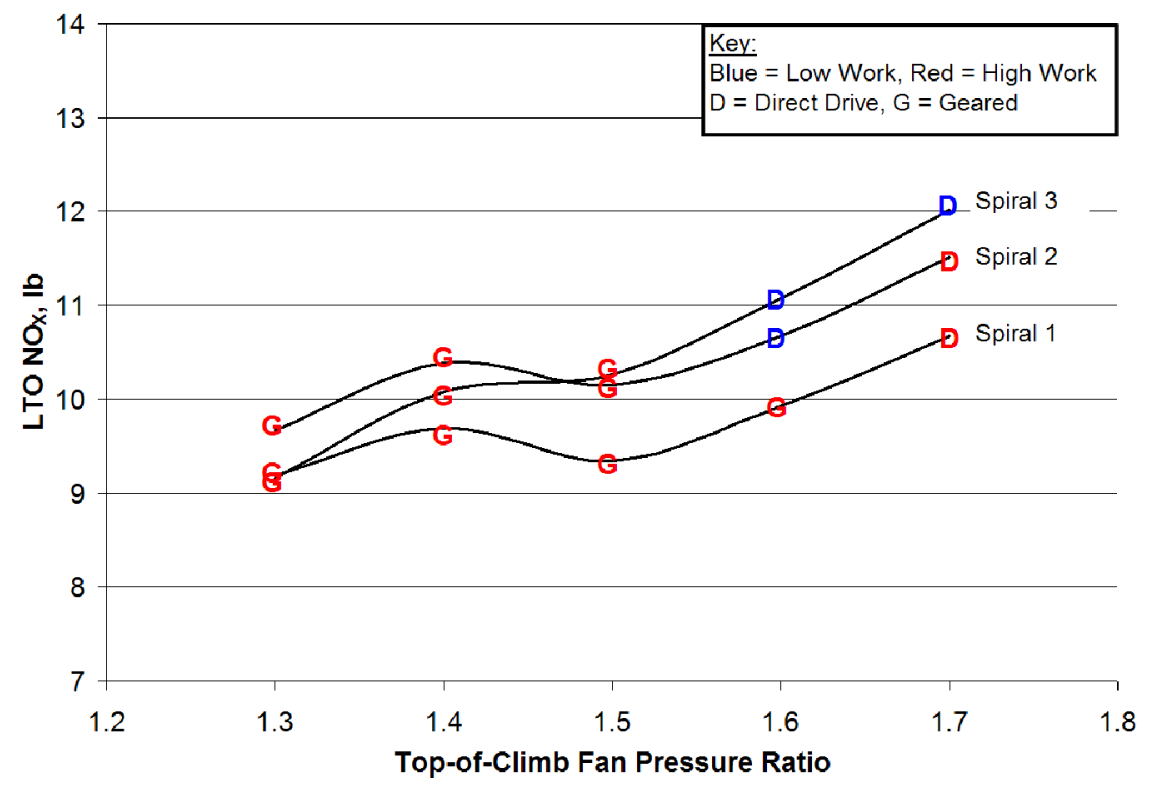

Figure 4. Variation of LTO $\mathrm{NO}_{\mathrm{x}}$ with fan pressure ratio ( $\mathrm{NO}_{\mathrm{x}}$ per LTO cycle). 


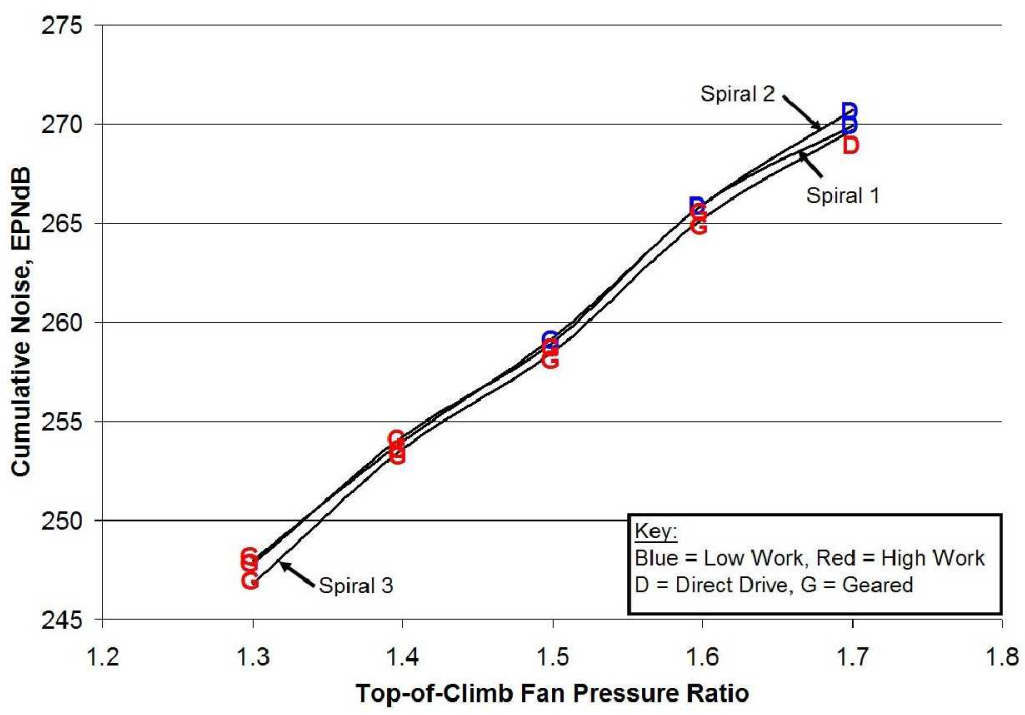

Figure 5. Variation of cumulative noise with fan pressure ratio.

As evidenced by the varying colors, letters, and trend lines in Figs. 1 though 5, the study results did not lead to a clear "winner" in terms of the best engine design for this application. The low fan pressure ratio, UHB engines studied do lead to lower aircraft noise, but at the expense of slightly higher fuel consumption and total $\mathrm{NO}_{\mathrm{x}}$ emissions. For an isolated engine, lower fan pressure ratio (higher bypass ratio) is beneficial for both reducing fuel consumption and reducing noise. However, once incorporated into an aircraft system, a desire for low noise and a desire for low fuel consumption may not lead to the same optimum fan pressure ratio. Aircraft noise and $\mathrm{LTO}_{\mathrm{NO}}$ are reduced by driving fan pressure ratio as low as practically possible, whereas optimum vehicle weight, block fuel, and block $\mathrm{NO}_{\mathrm{x}}$ occur towards the other end of the fan pressure ratio range analyzed. The relative importance of efficiency, noise, and emissions will dictate the overall best engine design.

Since no single engine provides the best performance across all of the metrics, there are a series of design tradeoffs that must be accepted. For example, choosing a low fan pressure ratio because of the noise benefits incurs an increase in fuel consumption compared to what could be achieved with a higher fan pressure ratio design. The magnitudes of these various trade-offs are presented in Table 3 for Spiral 2. For each metric column, the minimum value is used as the baseline for the remaining cases. The values in the remaining rows indicate the magnitude of the penalty incurred from selecting that particular engine, relative to the best possible result. For example, in Table 3 the direct drive, low work, FPR $=1.5$ case has $4.3 \%$ higher ramp weight than the minimum (direct drive, low work LPC, FPR=1.7); 1.1\% greater block fuel consumption than the minimum (direct drive, low work LPC, FPR=1.6); $12.8 \%$ greater block $\mathrm{NO}_{\mathrm{x}}$ than the minimum (direct drive, high work LPC, FPR=1.7); $0.8 \%$ greater LTO $\mathrm{NO}_{\mathrm{x}}$ than the minimum (geared, high work LPC, FPR=1.5); and 5.4 EPNdB higher cumulative noise than the minimum (geared, high work LPC, FPR=1.4). (The geared, FPR=1.3 and direct drive, FPR=1.4 cases were not included in the trade-off analysis because of practicality issues with those designs. The geared, FPR $=1.3$ engines have very large diameters, leading to an unrealistically long landing gear given the conventional under-wing propulsion-airframe integration approach assumed for the study. The direct drive, FPR $=1.4$, designs are an extreme case for the direct drive engine architecture. Under the design ground rules used for this study, the slow low-spool speed necessitates a large number of low pressure turbine (LPT) stages, leading to an extremely heavy and long engine. Both of these engines were carried through the complete set of analyses, however, in order to fully investigate performance trends as fan pressure ratio was decreased to the extreme.) 
Table 3. Spiral 2 Trade-Off Analysis

\begin{tabular}{|l|c|c|c|c|c|}
\hline & $\begin{array}{c}\text { Ramp } \\
\text { Weight }\end{array}$ & $\begin{array}{c}\text { Block } \\
\text { Fuel }\end{array}$ & $\begin{array}{c}\text { Block } \\
\text { NO }\end{array}$ & LTO NO & $\begin{array}{c}\text { Cum. } \\
\text { EPNdB }\end{array}$ \\
\hline Low, Geared, FPR=1.4 & $+8.6 \%$ & $+5.7 \%$ & $+21.6 \%$ & $+4.8 \%$ & +0.2 \\
\hline High, Geared, FPR=1.4 & $+7.3 \%$ & $+5.9 \%$ & $+15.8 \%$ & $+2.3 \%$ & Minimum \\
\hline Low, Geared, FPR=1.5 & $+3.1 \%$ & $+0.8 \%$ & $+11.9 \%$ & $+1.3 \%$ & +5.2 \\
\hline High, Geared, FPR=1.5 & $+2.3 \%$ & $+1.6 \%$ & $+5.8 \%$ & Minimum & +5.3 \\
\hline Low, Direct, FPR=1.5 & $+4.3 \%$ & $+1.1 \%$ & $+12.8 \%$ & $+0.8 \%$ & +5.4 \\
\hline High, Direct, FPR=1.5 & $+7.8 \%$ & $+6.2 \%$ & $+11.2 \%$ & $+2.8 \%$ & +5.8 \\
\hline Low, Geared, FPR=1.6 & $+2.8 \%$ & $+2.5 \%$ & $+10.7 \%$ & $+7.9 \%$ & +12.5 \\
\hline High, Geared, FPR=1.6 & $+1.3 \%$ & $+2.7 \%$ & $+3.1 \%$ & $+6.1 \%$ & +12.4 \\
\hline Low, Direct, FPR=1.6 & $+1.0 \%$ & Minimum & $+8.1 \%$ & $+5.1 \%$ & +11.9 \\
\hline High, Direct, FPR=1.6 & $+3.1 \%$ & $+3.7 \%$ & $+4.7 \%$ & $+5.9 \%$ & +12.5 \\
\hline Low, Direct, FPR=1.7 & Minimum & $+1.3 \%$ & $+1.2 \%$ & $+14.3 \%$ & +16.7 \\
\hline High, Direct, FPR=1.7 & $+1.6 \%$ & $+4.4 \%$ & Minimum & $+13.4 \%$ & +17.1 \\
\hline
\end{tabular}

For Spiral 2, pursuing minimum noise (geared, high work LPC, FPR=1.4), leads to a penalty in fuel consumption of $\sim 6 \%$. Conversely, pursuing minimum fuel consumption (direct drive, low work LPC, FPR=1.6) leads to $\sim 12$ EPNdB higher cumulative noise. Which design is better overall depends, in part, on the relative value of low noise and low fuel consumption to the airlines, which in turn depends on external factors such as fuel cost and airport noise restrictions. Similar analysis was also performed for Spirals 1 and 3 and, although the magnitudes of the tradeoffs varied slightly, the minimum cases for each metric and general conclusions were the same. Selecting a balanced design is somewhat subjective; however, for all three Spirals the FPR=1.5 cases seemed to offer the best overall performance. In particular, the low work, geared and direct drive cases and the high work, geared case have relatively good weight, fuel efficiency, noise, and emissions results. (The high work, direct drive, FPR=1.5 case has inferior performance to the other FPR $=1.5$ cases.) Bypass ratios for these engines are in the $\sim 12.5-14.5$ range, at the lower end of what is usually considered "ultra-high bypass ratio." It is interesting to compare the general characteristics of these engines to those of the geared engine being offered by Pratt and Whitney for the Bombardier CSeries aircraft. Although the details of the Pratt and Whitney engine are not publically known, there are some similarities in the general parameters. The target thrust level for the CSeries engine is $23,000 \mathrm{lb}^{26}$ the same SLS target thrust used in this study. The fan diameter for the CSeries engine is 73 inches, ${ }^{26}$ the same as the Spiral 1 and 2 $\mathrm{FPR}=1.5$ engines. Bypass ratio is expected to be $12,{ }^{27}$ again similar to the $\mathrm{FPR}=1.5$ engines in the study. Noise performance for the P\&W engine is projected to be Stage 4 minus 20 EPNdB. ${ }^{27}$ The FPR $=1.5$ configurations in this study result in a Stage 4 margin of $\sim 19-24$ EPNdB (the range reflects uncertainty in ANOPP flyover noise predictions).

The potential overall benefits of the advanced study vehicles compared to current aircraft were also assessed. The baseline for comparison was a 1998 EIS technology level vehicle (equivalent technology to 737-800/CFM567B), sized to match the design mission of the study vehicles. The advanced Spiral 1 vehicles offer up to a $15 \%$ reduction in ramp weight, up to a $24 \%$ reduction in block fuel consumption, up to a $73 \%$ reduction in block $\mathrm{NO}_{\mathrm{x}}$ (block fuel and $\mathrm{NO}_{\mathrm{x}}$ based on a $3250 \mathrm{~nm}$ mission), and up to a $58 \%$ reduction in $\mathrm{NO}_{\mathrm{x}}$ emissions per landing-takeoff cycle. These maximum potential reductions occur for different engines designs, and a single vehicle would not achieve all of these reductions. The advanced technology of the Spiral 2 vehicles offers even greater potential than the Spiral 1 vehicles for reducing fuel consumption compared to current single-aisle vehicles. The potential fuel consumption benefit is up to $29 \%$ and ramp weight could be up to $16 \%$ less. The Spiral 2 vehicles have less $\mathrm{NO}_{\mathrm{X}}$ reduction potential than Spiral 1 due to the higher emission indices associated with the higher overall pressure ratio engines. The advanced combustor technology assumed for these engines still results in large $\mathrm{NO}_{\mathrm{X}}$ emission 
reductions, however. Up to $64 \%$ reduction in block $\mathrm{NO}_{\mathrm{x}}$ emissions and $54 \%$ reduction in $\mathrm{NO}_{\mathrm{x}}$ per LTO cycle compared to the 1998 EIS technology baseline vehicle. The fuel consumption benefit of the ASAT, Spiral 3 configurations is up to a $29 \%$ reduction compared to a 737-800 equivalent technology airplane designed for the same mission ( $\mathrm{M}=0.72$ cruise with modified wing sweep, etc.), the same benefit as found in Spiral 2. Note however, that the reduction in fuel consumption of the Spiral 3 vehicles compared to a 737-800 type airplane ( $M=0.785)$ is slightly greater because of the additional benefit of lower cruise Mach. One area where the Spiral 3 technology benefits differ from Spiral 2 is block $\mathrm{NO}_{\mathrm{x}}$. The lower emission indices associated with the lower cruise Mach lead to a larger reduction in block $\mathrm{NO}_{\mathrm{X}}$ than in Spiral 2 (up to $69 \%$ compared to the 1998 EIS technology baseline airplane). In terms of noise benefits, the lowest noise practical ASAT configurations have almost a 25 EPNdB cumulative noise reduction compared to the 737-800.

\section{Conclusions}

- UHB engines are feasible for a 737/A320-class vehicle. In general, the larger diameter associated with UHB engines can be accommodated on this class of vehicle with relatively simple measures such as increased landing gear length or changes to wing dihedral (changes to wing dihedral were not explored in this study).

- Optimum engine fan pressure ratio depends on the metric of interest, as well as the ground rules, basic engine architectures, and assumptions used in the analysis. With the ground rules, architectures, and assumptions used in this study: empty and ramp weight (often surrogate indicators of cost) are minimized with high fan pressure ratio; block fuel consumption is minimized with a fan pressure ratio of $\sim 1.6$; block $\mathrm{NO}_{\mathrm{X}}$ emissions are minimized with high fan pressure ratio; and LTO $\mathrm{NO}_{\mathrm{x}}$ and certification noise are minimized with fan pressure ratio as low as possible. These fan pressure ratio trends do not change with variation in engine overall pressure ratio or design Mach number.

- The primary benefit of the geared fan approach is to enable viable propulsion systems at lower fan pressure ratios than possible with a direct drive fan. The geared fan approach is preferred for fan pressure ratios (top-ofclimb) below 1.5 (roughly BPR $>13$ ). At a fan pressure ratio of 1.5 , a low work LPC, direct drive engine can provide outcomes similar to a geared engine. Above a fan pressure ratio of 1.5 , a low work, direct drive engine provides a better overall aircraft system (for the metrics tracked in this study) than the geared engines.

- If the design goal is to minimize ramp weight, block fuel, or block $\mathrm{NO}_{\mathrm{x}}$, for the engines in this study geared fan engine technology is not necessary (since the minimums for these metrics occur at fan pressure ratios greater than 1.5.)

- If the design goal is to minimize airport area environmental impacts (i.e., aircraft noise and LTO $\mathrm{NO}_{\mathrm{x}}$ ), a geared system would be the preferred approach because it enables a practical low fan pressure ratio engine design.

- Among the cases analyzed, the best balanced designs, performing well across all the metrics of interest (ramp weight, fuel consumption, emissions, and noise), are fan pressure ratio 1.5 designs; either the high work LPC with a geared fan, or the low work LPC with either a geared or direct drive fan.

- Relative to 1998 EIS technology, the advanced configurations studied have the potential for significant benefits: up to $29 \%$ reduction in fuel consumption and greater than 24 EPNdB cumulative noise reduction. These benefits do not occur with the same engine design, however. The minimum fuel consumption designs have $\sim 12$ EPNdB (cumulative) higher noise than the minimum noise designs and the minimum noise designs have up to $6 \%$ higher fuel consumption than the minimum fuel consumption designs.

\section{Acknowledgments}

The authors would like to thank Fay Collier for his support of this study while Principal Investigator for the Subsonic Fixed Wing Project of NASA's Fundamental Aeronautics Program. Craig Nickol and Dennis Bartlett (ret.) of NASA Langley Research Center are acknowledged for their review and critique of the study approach and results.

\section{References}

${ }^{1}$ Norris, G., "THE 737 STORY: Smoke and mirrors obscure 737 and Airbus A320 replacement studies," Flight International, 7 Feb. 2006.

${ }^{2}$ Lyon, T. A., and Hillery, R. D., "Geared Fan Engine Systems - Their Advantages and Potential Reliability," AIAA 72-1173, November 1972.

${ }^{3}$ Dunican, M. G., "Installation of Innovative Turbofan Engines on Current Transport Airplanes," AIAA 87-2921, September 1987. 

2003.

${ }^{4}$ Daggett, D. L., Brown, S. T., and Kawai, R. T., "Ultra-Efficient Engine Diameter Study," NASA CR-2003-212309, May

5“'Current Market Outlook 2008." Boeing Commercial Airplanes, 2008.

${ }^{6}$ Guynn, M. D., Berton, J. J., Fisher, K. L., Tong, M. T, and Thurman, D. R, "Engine Concept Study for an Advanced SingleAisle Transport," NASA TM-2009-215784, 2009.

${ }^{7}$ Lytle, J.K., "The Numerical Propulsion System Simulation: An Overview," NASA TM-2000-209915.

${ }^{8}$ NPSS User Guide Software Release: NPSS 1.6.3 AL.

${ }^{9}$ NPSS Reference Sheets Software Release: NPSS_1.6.3 AL.

${ }^{10}$ Onat, E., and Klees, G., "A Method to Estimate Weight and Dimensions of Large and Small Gas Turbine Engines," NASA CR 159481, 1979.

${ }^{11}$ Tong, M.T., Halliwell, I., Ghosn, L.J., "A Computer Code for Gas Turbine Engine Weight and Life Estimation," ASME Journal of Engineering for Gas Turbine and Power, volume 126, no. 2, April 2004.

${ }^{12}$ Tong, M.T., Naylor, B.A., "An Object-Oriented Computer Code for Aircraft Engine Weight Estimation," GT2008-50062, ASME Turbo-Expo 2008, June 9-13, 2008.

${ }^{13}$ McCullers, L., "Aircraft Configuration Optimization Including Optimized Flight Profiles," Proceedings of the Symposium on Recent Experiences in Multidisciplinary Analysis and Optimization, NASA CP 2327, April 1984.

${ }^{14}$ Ardema, M. D., Chambers, M. C., Patron, A. P, Hahn, A. S., Miura, H., and Moore, M. D., "Analytical Fuselage and Wing Weight Estimation of Transport Aircraft," NASA TM 110392, May 1996.

15،737 Airplane Characteristics for Airport Planning," D6-58325-6, Boeing Commercial Airplanes, October 2005.

${ }^{16}$ Torenbeek, E., Synthesis of Subsonic Airplane Design. Kluwer Academic Publishers, Dordrecht, 1982, pp. 553-554.

${ }^{17}$ Gillian, R. E., "Aircraft Noise Prediction Program User's Manual," NASA TM-84486, 1983.

${ }^{18}$ Zorumski, W. E., "Aircraft Noise Prediction Program Theoretical Manual," NASA TM-83199, 1981, Parts 1 and 2.

19“Noise standards: Aircraft type and airworthiness certification," Code of Federal Regulations, Title 14, Chapter I, Part 36.

${ }^{20}$ Burley, C.L., Rawls, J.W., Jr., Berton, J.J., and Marcolini, M.A., “Aircraft System Noise Prediction," NASA report to be published, 2009.

${ }^{21}$ Stone, J.R., Krejsa, E.A., Clark, B.J., and Berton, J.J., "Jet Noise Modeling for Suppressed and Unsuppressed Aircraft in Simulated Flight," NASA TM-2009-215524, 2009.

${ }^{22}$ Janardan, B.A., Hoff, G.E., Barter, J.W.; Martens, S., Gliebe, P.R., Mengle, V., and Dalton, W.N., "AST Critical Propulsion and Noise Reduction Technologies for Future Commercial Subsonic Engines - Separate-Flow Exhaust System Noise Reduction Evaluation," Final Report: NAS3-27720, Area of Interest 14.3, General Electric Report R98AEB152, May 1998.

${ }^{23}$ Kontos, K.B., Kraft, R.E., and Gliebe, P.R., "Improved NASA-ANOPP Noise Prediction Computer Code for Advanced Subsonic Propulsion Systems. Volume 2: Fan Suppression Model Development," NASA CR-202309, 1996.

${ }^{24}$ Neubert, R., Bock, L., Malmborg, E., and Owen-Peer, W., "Advanced Low Noise Research Fan Stage Design," NASA CR 97-206308, 1997.

${ }^{25}$ Jones, M., Parrott, T., Sutliff, D., Hughes, C., "Assessment of Soft Vane and Metal Foam Engine Noise Reduction Concepts," AIAA-2009-3142, 2009.

${ }^{26}$ Norris, G., "Simplified GTF," Aviation Week and Space Technology, Vol. 168, No. 9, 3 Mar. 2008, pp. 26-27.

${ }^{27}$ Flint, P., "Gearing Up for the Future," Air Transport World, February 2008. 